\title{
Clinical-imagistic aspects of supernumerary teeth
}

\author{
Aspecte clinico-imagistice ale dinţilor supranumerari
}

\author{
Mioara Decusară, Cerasella Dorina Şincar, Gina Păunița Grecu, \\ Gabriela Popa,Gabriel Valeriu Popa \\ Departamentul de Medicină Dentară, Facultatea de Medicină şi Farmacie, \\ Universitatea „Dunărea de Jos“, Galaţi, România
}

\begin{abstract}
Supernumerary teeth represent isolated dental abnormalities by dental excess occurring when the disruptive factor acts in the stage of dental formation (induction and proliferation). It may be the result of the intervention of some hereditary, phylogenetic, local factors (disturbing factors in the dental proliferation stage), but may appear as clinical manifestations in genetic syndromes (cleido-cranial dysplasia and Gardner's syndrome). It determines aesthetic, occlusal, periodontal, clinical and functional changes, the diagnosis of certainty being given by radiological investigations. Since supernumerary teeth do not affect the quality of the alveolar bone, the prognosis is favorable, and surgical (extraction) and orthodontic treatment restores the normal aesthetic and functional aspect of the dental-maxillar apparatus.
\end{abstract}

Keywords: supernumerary teeth, mesiodens, radiological aspects, surgical-orthodontic treatment

\begin{abstract}
REZUMAT
Dinții supranumerari reprezintă anomalii dentare izolate de număr, prin exces dentar, care apar atunci când factorul perturbator acţionează în stadiul de formare a lamei dentare (de inducţie şi proliferare). Pot fi consecinţa intervenţiei unor factori etiologici ereditari, filogenetici, locali (perturbatori în etapa de proliferare a lamei dentare), dar pot apărea ca manifestări clinice în sindroame genetice (displazia cleido-craniană şi sindromul Gardner). Determină modificări fizionomice, ocluzale, parodontale, clinice şi funcţionale, diagnosticul de certitudine fiind dat de investigaţii radiologice. Având în vedere că dinţii supranumerari nu afectează calitatea osului alveolar, prognosticul este favorabil, iar prin tratament chirurgical (extracţie) şi tratament ortodontic se reface aspectul estetic şi funcţional normal al aparatului dentar-maxillar.
\end{abstract}

Cuvinte cheie: dinţi supranumerari, mesiodens, aspecte radiologice, tratament chirurgical-ortodontic

\section{INTRODUCERE}

Dinţii supranumerari apar frecvent în regiunea incisivilor superiori (meziodens), a premolarilor sau molarilor (paramolar) sau a molarilor de minte (distomolar), având forma normală sau atipică (forma conoidă, de ţăruş) (1). Factorii etiologici implicaţi în apariţia lor sunt multipli: expresie a unor modificări filogenetice ale dentaţiei, ereditari, consecinţă a unei hiperactivităţi de inducţie a lamei dentare de către ectomezenchim, expresia unei displazii ectodermale sau a divizării mugurilor dentari sau pot fi de cauze locale (inflamaţii sau infecţii) $(2,3)$.

Dinţii supranumerari pot fi unici sau multipli, cel mai frecvent la dentiţia definitivă, la nivelul maxilarului superior, în regiunea incisivă, dar şi în regiunile premolar şi molar. Pot fi asociaţi cu alte anomalii dentare izolate, precum anodonţii, incluzii, microdenţie, displazii structurale, discoloraţii, malpoziţii. Când rămân incluşi intraos, prezenţa dinţilor supranumerari este asimptomatică, fiind descoperită uneori întâmplător la un examen radiologic de rutină $(4,5,6)$ (Fig. 1-7). 


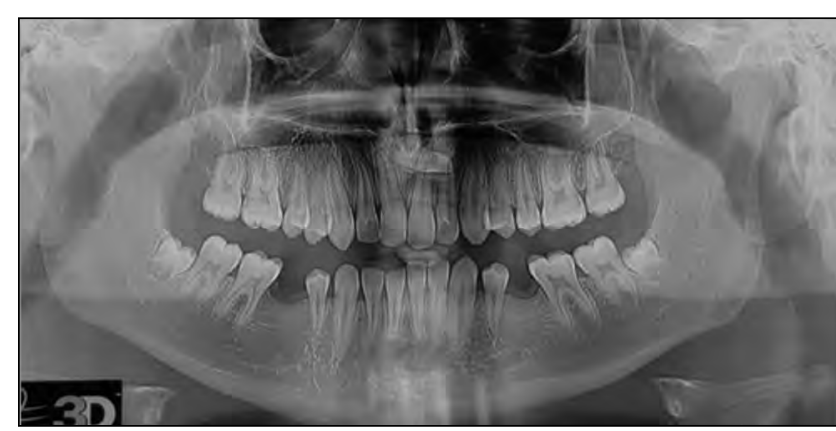

FIGURA 1. Pe ortopantomogama unui pacient de 15 ani, care a solicitat consult ortodontic pentru tratamentul ocluziei inverse frontale, se observă un meziodens inclus orizontal, anodonții de premolari secunzi mandibulari şi de molari de minte maxilari

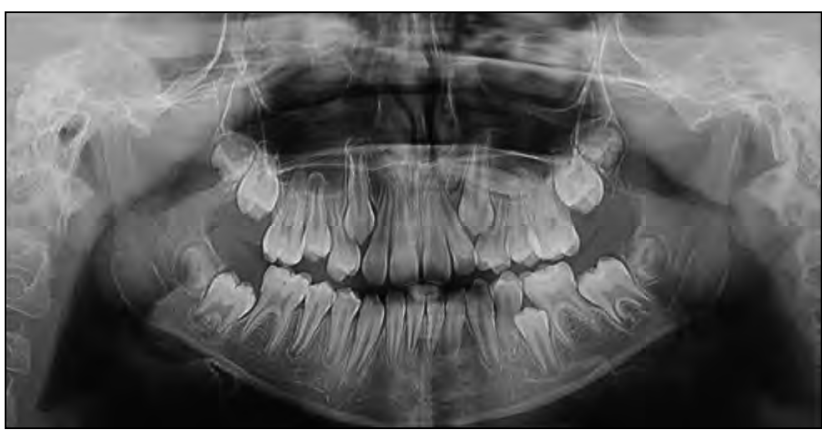

FIGURA 2. Ortopantomograma unui pacient ce a solicitat tratament ortodontic pentru rezolvarea înghesuirii dentare maxilare şi mandibulare a arătat prezența unui meziodens inclus profund orizontal, care „pluteşte“ spre distal deasupra apexurilor lui 21, 24, 25, fără a produce rizaliză patologică

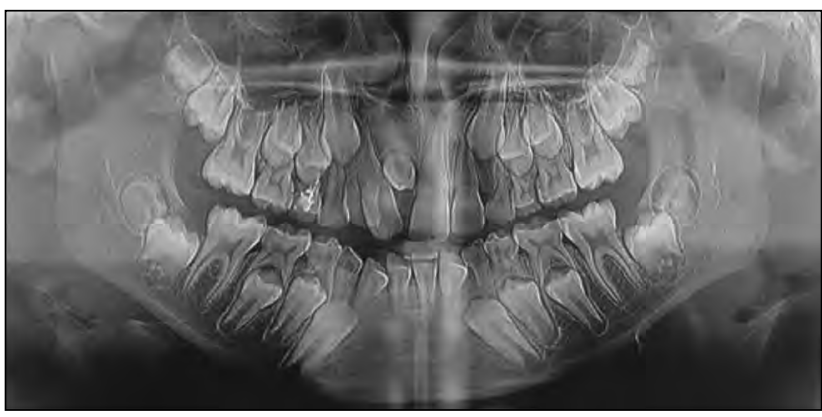

FIGURA 3. Ortopantomograma unui pacient de 9 ani cu dentiție mixtă prezintă un meziodens inclus între 11 şi 21, în poziție orizontală antero-posterioară, care a determinat malpoziții ale lui 11 şi 12

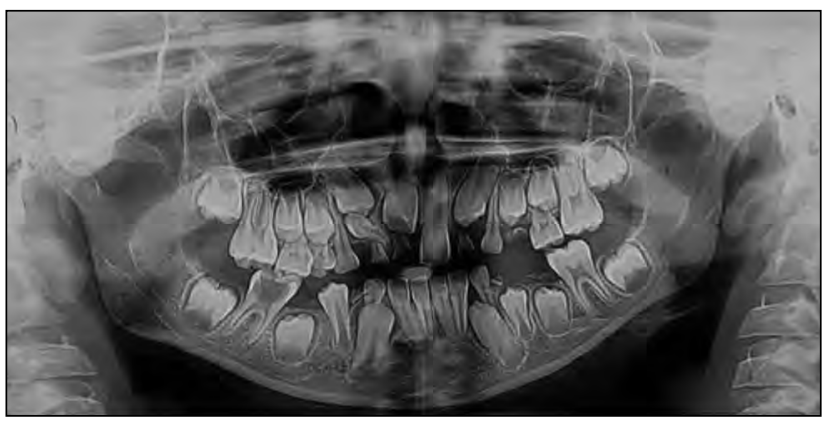

FIGURA 4. Ortopantomograma unui băiat de 10 ani evidențiază anodonții de incisivi laterali superiori şi de molari de minte, precum şi prezența unui meziodens inclus anastrofic, care blochează erupția lui 11 şi 13

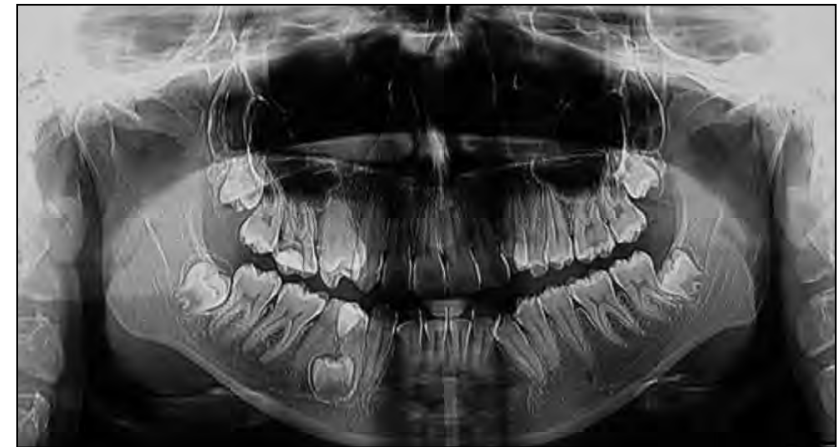

FIGURA 5. Pe ortopantomograma unei paciente de 15 ani ce a solicitat tratament ortodontic pentru rezolvarea înghesuirii dentare bimaxilare se evidențiază prezența unui paramolar, între rădăcinile lui 44 şi 45, în stadiul de mineralizare coronară

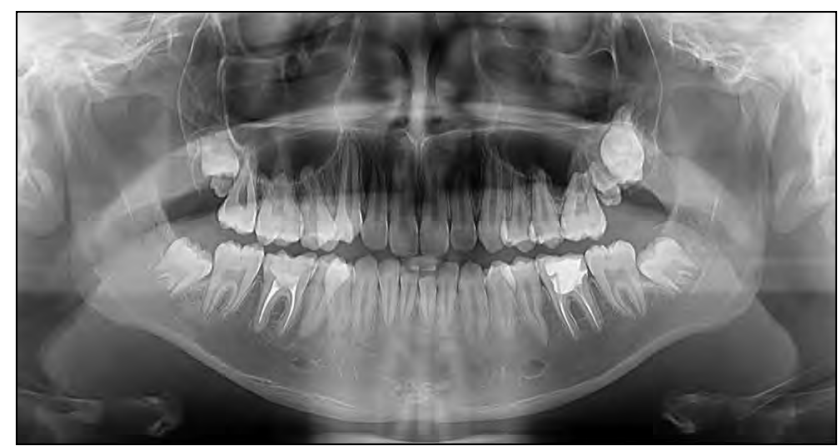

FIGURA 6. Pe ortopantomograma unui băiat de 15 ani se observă prezența de distomolari la arcada maxilară, bilateral, care blochează erupția lui 18 şi 27

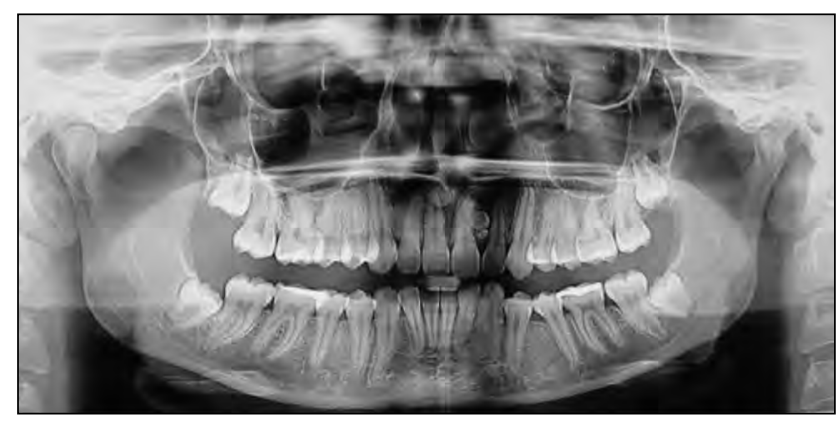

FIGURA 7. Imaginea panoramică a doi denticuli între rădăcinile lui 21 şi 22, care au determinat o uşoară curbare a apexului lui 21

Dinţii supranumerari determină tulburări fizionomice, înghesuiri dentare, deplasări sau rotaţii ale dinţilor erupţi adiacenţi, blocaje ocluzo-articulare, resorbţii radiculare ale dinţilor din seria normală, fie direct (ca rezultat al erupţiei), fie indirect (ca rezultat al incluziei) (4,6) (Fig. 8-11).

Tratamentul dinţilor supranumerari este chirurgical-ortodontic şi constă în $(2,4)$ :

- Extracţia dintelui supranumerar, cu eliberarea drumului de erupţie a dintelui din seria normală şi ancorarea acestuia, când a rămas inclus intraosos 
- După crearea de spaţiu pentru erupţia şi alinierea dintelui inclus, se tracţionează cu forţe ortodontice lente, cu ajutorul unui aparat ortodontic.

Durata tratamentului ortodontic este diferită, în funcţie de situaţia clinică, modificările ocluzale şi fizionomice pe care le-a determinat, precum şi asocierea cu alte anomalii dentare izolate.

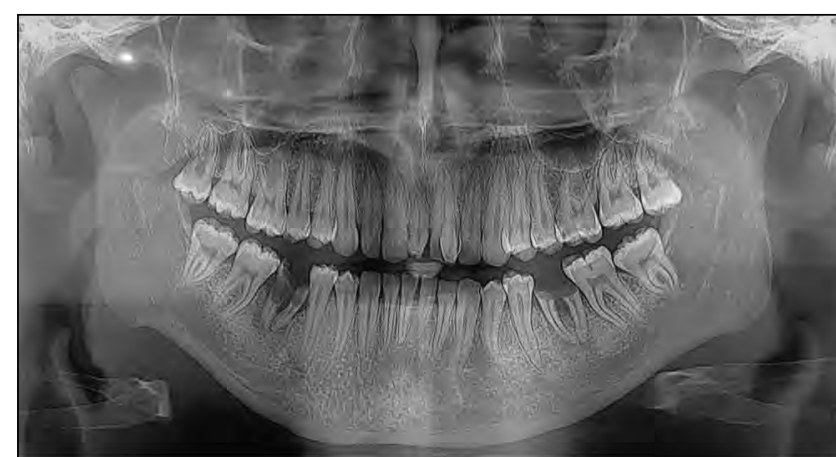

FIGURA 8. Ortopantomograma unui pacient de 21 ani evidențiază prezența a doi meziodenşi, erupți şi aliniați pe arcada superioară

\section{PREZENTARE DE CAZ}

Pacientul S.E., în vârstă de 13 ani, a solicitat consult ortodontic, la recomandarea medicului sto-
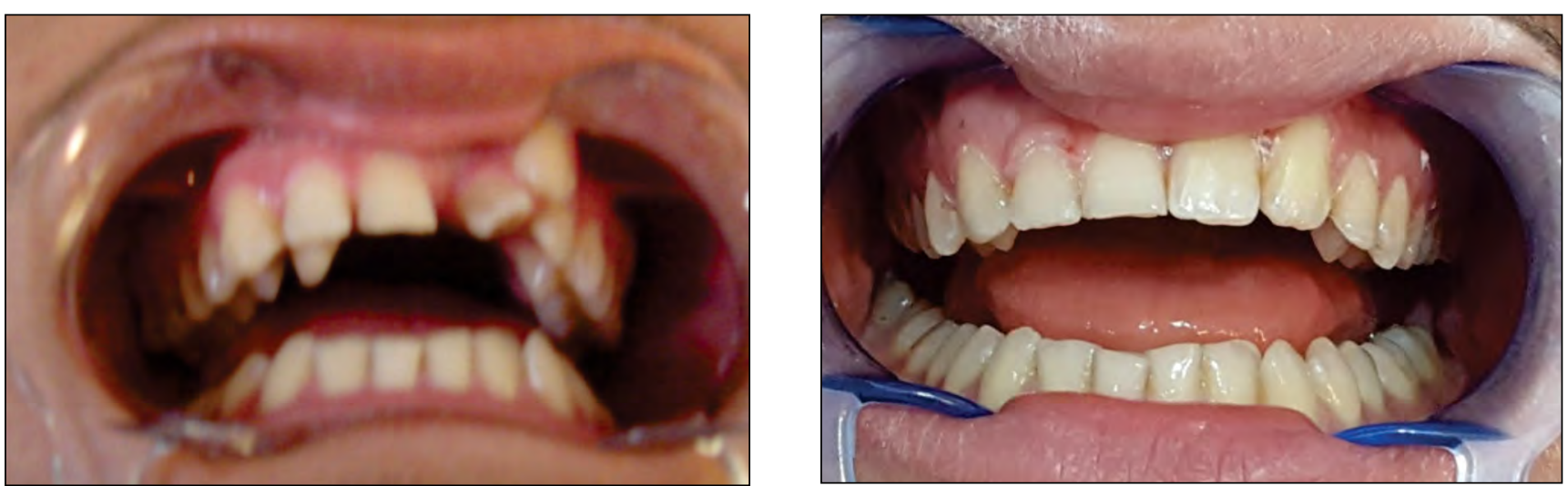

FIGURA 9. Pacient de 16 ani tratat ortodontic pentru doi dinți supranumerari erupți pe arcada superioară (înainte şi după tratament)
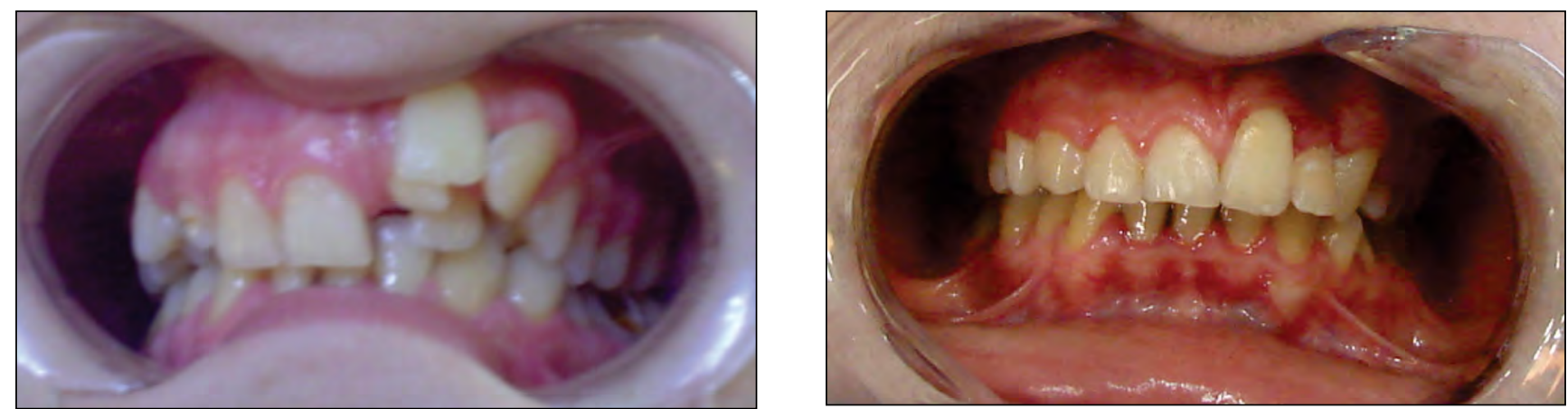

FIGURA 10. Pacient de 14 ani care prezenta un meziodens erupt între coroanele lui 21 şi 22 şi persistența lui 53 , cu 13 inclus (înainte şi după tratament ortodontic) matolog generalist, ca urmare a întârzierii în erupţie a unui incisiv central superior, cu menţinerea spaţiului necesar pentru erupţia şi alinierea acestuia. Din anamneză a reieşit că permutarea dinţilor s-a desfăşurat în limite normale, cu excepţia lui 21, absent (rămas inclus intraosos), fără ca pacientul să fi suferit un traumatism.

La examenul clinic general şi facial al pacientului s-au constatat: normosomie şi normotonie, facies oval simetric şi proporţia etajelor figurii, profil convex cu punctul subnazale anterior de planul nazofrontal. cu macrocheilie superioară.

Examenul clinic intraoral a evidenţiat (Fig. 12):

- Dentiţie definitivă, cu leziune carioasă în gropiţa vestibulară a lui 46 , tratată cu obturaţie din compozit fotopolomerizabil

- Absenţa lui 21, cu spaţiu existent pentru erupţie şi aliniere, cu palparea în vestibulul bucal, subnazal, a unei formaţiuni dentare

- Premolarii secunzi inferiori în erupţie lingualizată, cu angranaje lingualizate între 15-43 şi $25-35$

- Recesiune parodontală la nivelul lui 31

- Relaţii sagitale neutrale la nivel molar şi canin bilateral (clasa I Angle) şi la nivelul incisivilor 

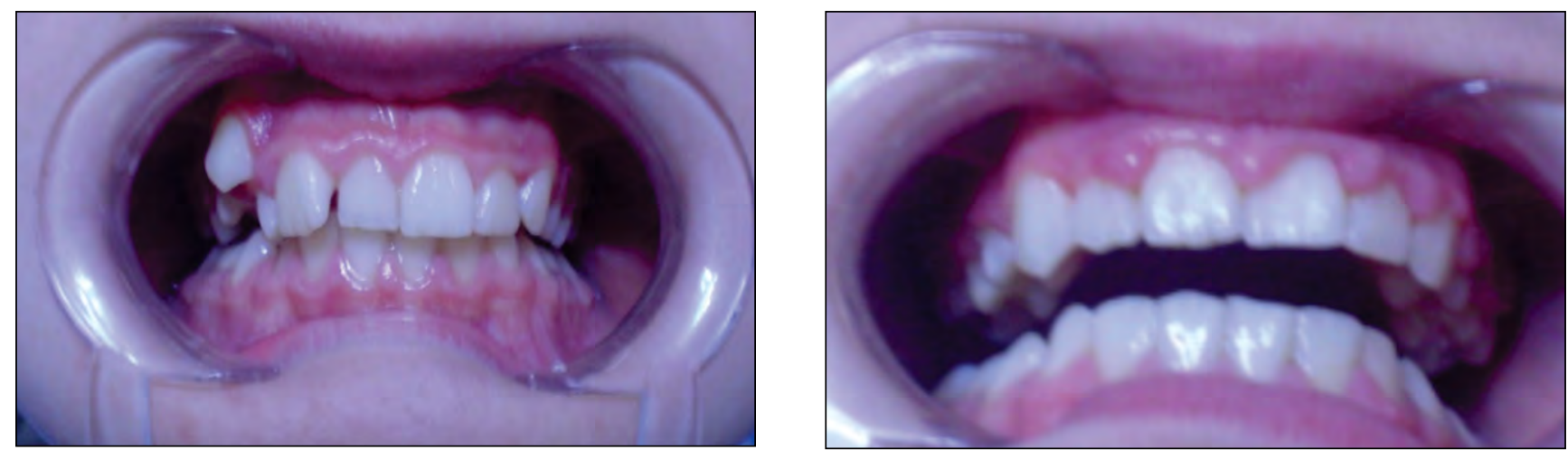

FIGURA 11. Pacientă de 12 ani cu un meziodens erupt între 11 şi 21, cu reducerea spațiului pentru alinierea lui 12 şi 13 (înainte şi după tratamentul ortodontic)
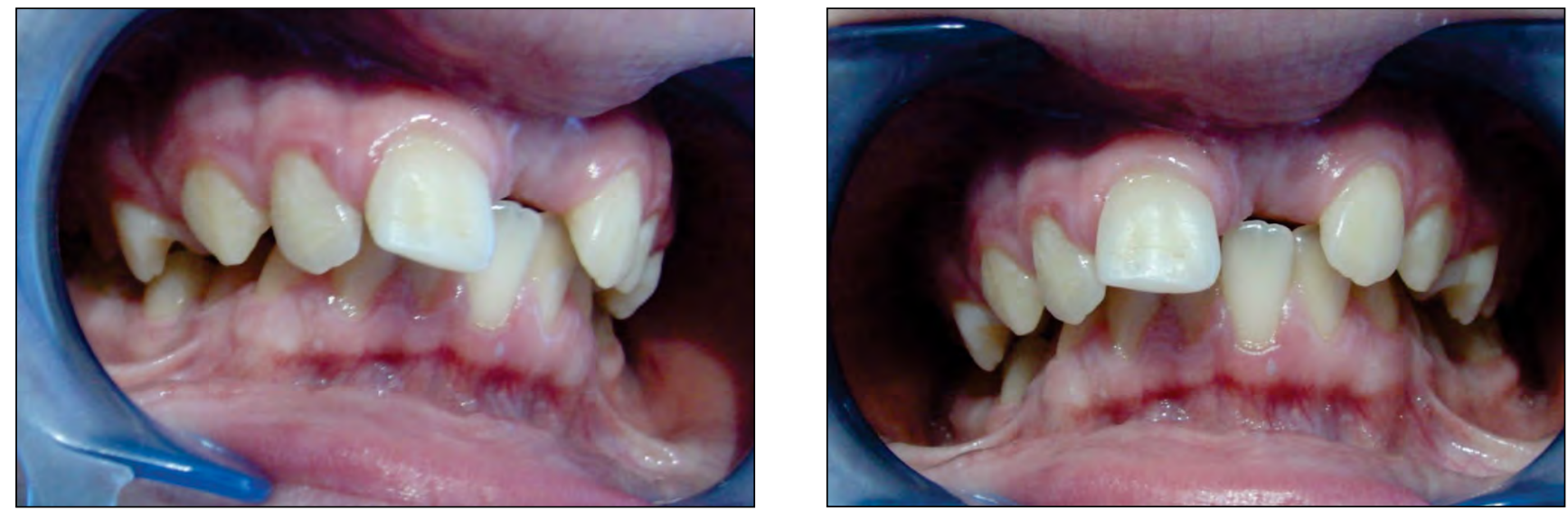

FIGURA 12. Imaginea arcadelor dentare înaintea începerii tratamentului ortodontic

- Corespondenţa liniilor mediane şi interincisive maxilare şi mandibulare

- Supraacoperire laterală de $1 / 2$, iar frontală de $3 / 4$.

Ortopantomograma efectuată înaintea tratamenului ortodontic a evidenţiat (Fig. 13):

- Un dinte supranumerar (meziodens), cu rădăcina în formare, situat intraosos între 21, provocându-i înclinarea mezio-vestibulară şi blocarea în erupţie, şi rădăcina lui 22, erupt şi aliniat pe arcadă.

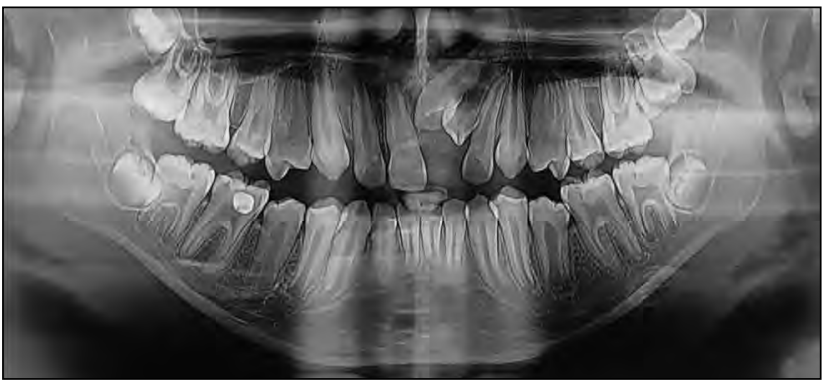

FIGURA 13. Ortopantomograma pacientului S.E. evidențiază prezența lui 21 inclus din cauza unui meziodens, cu rădăcina în formare, interpus între 21 şi 22
- Premolarii secunzi înferiori şi molarii secunzi cu rădăcinilie în formare (1/3 apicală)

- Prezenţa celor 4 muguri ai molarilor de minte, cu coroanele mineralizate, cu spaţii reduse pentru erupţie şi aliniere

Planul de tratament propus şi acceptat de pacient şi familie a fost:

- Aplicarea aparatului ortodontic fix, cu bracketuri metalice SWT, pentru început la arcada superioară, pentru aliniere şi nivelare dentară şi menţinerea spaţiului pentru tracţiunea ortodontică a lui 21 .

- Intervenţie chirurgicală pentru extracţia meziodensului şi aplicarea unui ataş ortodontic la nivelul coroanei lui 21, în vederea ancorării la aparatul ortodontic, tracţionării vestibulare şi alinierii pe arcada dentară

- Aplicarea aparatului fix ortodontic şi la nivelul arcadei dentare mandibulare, pentru nivelare şi aliniere, menţinerea relaţiilor neutrale la nivel canin şi molar, a corespondenţei liniilor mediane şi interincisive, cu obţinerea in- 
tercuspidării maxime şi relaţiilor funcţionale mandibulare în limite fiziologice

După o lună de la aplicarea aparatului fix la arcada dentară maxilară, s-a efectuat intervenţia chi-
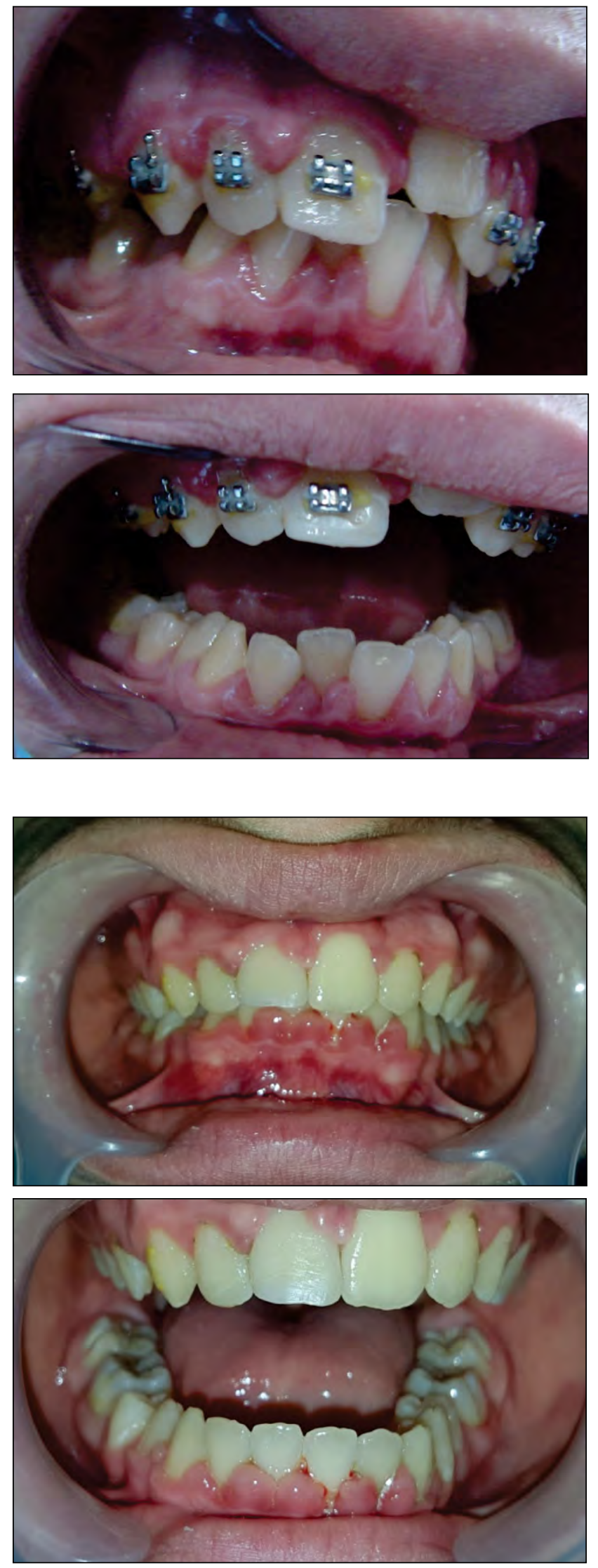

rurgicală prin care s-a extras meziodensul inclus, s-a descoperit coroana lui 21, pe care s-a aplicat un buton ortodontic cu ligatură metalică şi catenă elastică, cu care s-a realizat tracţionarea elactică şi ves-

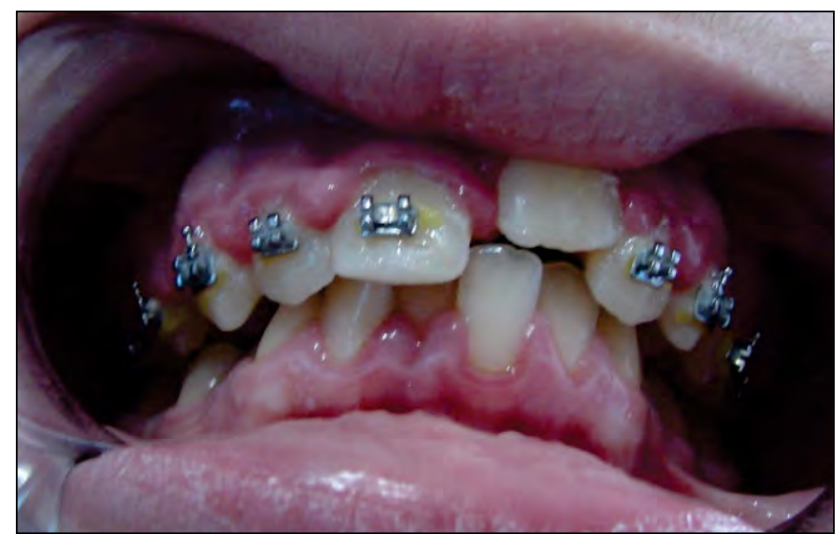

FIGURA 14. Faza intermediară a tratamentului ortodontic fix, după vestibularizarea lui 21 şi înaintea aplicării bracketurilor la arcada dentară mandibulară

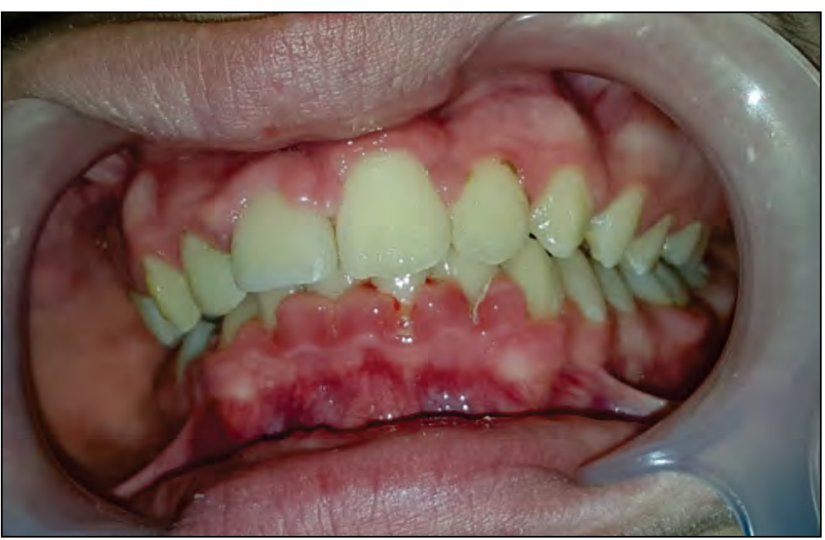

FIGURA 15. Aspectul arcadelor dentare după îndepărtarea aparatului ortodontic fix bimaxilar 
tibularizarea incisivului central inclus intraosos. La 5 luni de la intervenţia chirurgicală, s-a observat apariţia coroanei lui 21 la nivelul vestibulului bucal superior, iar la 12 luni de la începutul tratamentului ortodontic s-a aplicat aparat fix şi la nivelul arcadei dentare mandibulare şi s-a înlocuit ataşul de pe 21 cu un bracket, pentru a obţine alinierea şi nivelarea acestuia pe arcada dentară maxilară (Fig. 14).

După 26 de luni a fost îndepărtat aparatul ortodontic fix bimaxilar, obţinându-se obiectivele terapeutice stabilite la începutul tratamentului, iar contenţia a fost realizată cu gutiere termoformabile, utilizate noaptea, timp de 18-24 luni. S-a recomandat control la 6-8 luni, cu dispensarizarea erupţiei molarilor de minte şi extracţia acestora, pentru prevenirea recidivei ortodontice (Fig. 15).

\section{CONCLUZII}

Dinţii supranumerari apar prin proliferarea sporadică sau ereditară a lamei dentare. Diagnosticul

\section{BIBLIOGRAFIE}

1. Cobourne MT, DiBiase AT. Handbook of orthodontics. Ed. Mosby Elsevier, Philadelphia, 2010.

2. Ionescu Ecaterina. Anomaliile dentare. Ed. Cartea Universitară, Bucureşti, 2006

3. Eleonora Schiller. Anomalii dentare. Ed. Mirton, Timişoara, 2005

4. Glăvan Florica şi colab. Ortodonţie şi ortopedie dento-facială. Ed. Eubeea, Timişoara, 2008 se pune prin prezenţa dintelui supranumerar erupt şi aliniat pe arcadă, determinând de multe ori înghesuiri dentare, dar şi prin examenul radiologic, care depistează dintele din seria normală rămas de multe ori inclus intraosos, din cauza unui dinte supranumerar, prezent sau nu pe arcadă (6). Prezenţa dinţilor supranumerari produce tulburări în erupţia dinţilor definitivi, tulburări ocluzale şi probleme parodontale, datorate incongruenţei dento-alveolare cu înghesuire, dar mai ales tulburări fizionomice, prin blocarea în erupţie a dintelui din seria normală sau a malpoziţiilor acestora, când dinţii supranumerari au erupt. Prognosticul afecţiunii este favorabil, deoarece calităţile osului alveolar nu sunt afectate, iar prin extracţia dintelui supranumerar şi tratament ortodontic se reface aspectul estetic şi funcţional normal al aparatului dentar $(1,7)$.

5. Mioara Decusară, Gabriel Valeriu Popa, Cerasella Dorina Şincar. The relevance of orthopantomograms use in orthodontic practice. J Med Res Prac, 2017, 6(6): 189-194.ISSN: 2162-6391 2162-6375

6. Decusară Mioara. Utilizarea ortopantomogramei în practica stomatologică. Ed. Zigotto, Galaţi, 2017

7. Stanciu D, Dorobăţ Valentina. Ortodonţie şi ortopedie dento-facială. Ed. Medicală, Bucureşti , 2017 